\title{
К ВОПРОСУ О СУБЪЕКТНОМ СОСТАВЕ КОРПОРАТИВНОГО ДОГОВОРА
}

\author{
М. А. Гребенюк \\ Байкальский государственный университет, г. Иркутск, Российская Федерация
}

Информация о статье

Дата поступления

15 июня 2017 г.

Дата принятия к печати 20 ноября 2017 г.

Дата онлайн-размещения 27 ноября 2017 г.

\section{Ключевые слова}

Корпоративный договор; хозяйственное общество; субъекты корпоративного договора; доверительный управляющий ценными бумагами; будущий участник хозяйственного общества

\begin{abstract}
Аннотация
В настоящей статье сделана попытка определить круг субъектов, имеющих право на заключение корпоративного договора. Изучена потенциальная возможность заключения корпоративных соглашений учредителями хозяйственного общества, его будущими участниками, третьими лицами (кредиторами, инвесторами и др.), номинальными держателями ценных бумаг, доверительными управляющими ценными бумагами, а также хозяйственным обществом, по поводу осуществления прав участия в котором заключается корпоративный договор. По результатам исследования сделан вывод о том, что в качестве стороны корпоративного договора наряду с участниками хозяйственного общества при соблюдении определенного ряда условий могут выступать учредители хозяйственного общества, его будущие участники и доверительные управляющие.
\end{abstract}

\section{ABOUT THE PROBLEM OF PARTIES TO THE CORPORATE AGREEMENT}

\section{Maria A. Grebenyuk \\ Baikal State University, Irkutsk, Russian Federation}

\section{Article info}

Received

June 15, 2017

Accepted

November 20, 2017

Available online

November 27, 2017

\section{Keywords}

Corporate agreement; business entity; parties to the corporate contract; trustee; future participant of a business entity

\begin{abstract}
In this article, an attempt has been made to determine subjects of law that have the right to conclude a corporate agreement. The author studied the capability of the founders of a joint stock company, future participants of a joint stock company, third parties (creditors, investors and etc.), nominal holders of securities, entrusted managers of securities and also of the joint stock company of to conclude corporate agreements regarding the exercise of the rights of participation in it the corporate agreement is concluded. Based on the results of the research, the author concluded that a party to the corporate agreement could be (apart from the participants of the business entity) the founders of the company, its future participants and entrusted managers.
\end{abstract}

Научное сообщество долгое время ратовало за принятие норм о корпоративных соглашениях ввиду неопределенности их правового статуса. Однако появление в отечественном законодательстве норм об отдельных видах корпоративного договора - акционерном соглашении и договоре об осуществлении прав участников общества с ограниченной ответственностью, а затем и о корпоративном договоре - не привело к решению вопросов, касающихся правового регулирования указанных соглашений. Более того, такие принципиальные вопросы, как правовая природа, предмет корпоративного договора, гражданско-правовая ответственность сторон за нарушение его условий, до сих пор являются дискуссионными. Также не получил однозначного решения значимый как с практической, так и с теоретической стороны вопрос о субъектном составе корпоративного договора.

Попытки установить круг субъектов, имеющих право на заключение корпоративного договора, в науке предпринимались неодно- 
кратно, однако единое мнение так и не было сорормировано.

Анализ научных работ по исследуемой проблеме позволяет сделать вывод о наличии в отечественной юридической науке двух основных подходов к решению вопроса о субъектном составе корпоративного договора.

Сторонники первого (узкого) подхода полагают, что правом на заключение корпоративных договоров наделены только прямо указанные в законе субъекты, т. е. участники хозяйственных обществ $[1$, с. $6 ; 2$, с. $52 ; 3$, c. 36]. По мнению ученых, основным и обязательным условием, которому должен отвечать субъект, для того чтобы иметь право на заключение корпоративного договора, является владение акциями, долей в уставном капитале общества с ограниченной ответственностью.

Представители данного подхода также отмечают, что предоставление широкому кругу субъектов права заключать корпоративные соглашения противоречит установленной в российском законодательстве правовой конструкции корпоративного договора, который по своей природе является гражданско-правовым договором. Кроме того, наделение любых третьих лиц правом заключать корпоративный договор создаст возможности для «теневого корпоративного контроля, когда такие “третьи» лица будут, например, давать акционерам указания о голосовании тем или иным образом на общем собрании» [2, с. 72].

По мнению сторонников второго (широкого) подхода, круг субъектов корпоративного договора не должен и не может ограничиваться только участниками хозяйственных обществ [4, с. 9; 5, с. $102 ; 6$, с. $32 ; 7$, с. 152]. Наряду с ними среди возможных субъектов корпоративного договора ученые называют учредителей хозяйственного общества, его будущих участников, доверительных управляющих ценными бумагами и их номинальных держателей, хозяйственное общество, по поводу осуществления прав участия в котором заключается корпоративный договор, а также иных третьих лиц (кредиторов, инвесторов, залогодержателей и др.).

Если узкий подход основан на буквальном толковании законодательства, то сторонники широкого подхода обосновывают свою точку зрения отсутствием в нормах о корпоративных соглашениях прямого запрета на заключение корпоративных соглашений иными, чем участники хозяйственных обществ, субъектами. Кроме того, как отмечают ученые, каких-либо правовых оснований ограничивать состав участников корпоративного договора нет $[4$, с. $10 ; 5$, с. 104$]$.

Для решения вопроса о субъектном составе корпоративного договора необходимо исследовать потенциальную возможность участия в заключении корпоративного договора всех перечисленных выше субъектов. Для этого обратимся к законодательству, регулирующему корпоративные соглашения.

Так, п. 1 ст. 672 Гражданского кодекса Российской Федерации предусмотрено, что договор об осуществлении своих корпоративных прав вправе заключить участники хозяйственного общества или некоторые из них ${ }^{1}$.

В п. 1 ст. $32^{1}$ Федерального закона «Об акционерных обществах» от 26 декабря 1995 г. № 208-Ф3 (далее - Закон об АО) акционерное соглашение определяется как договор об осуществлении прав, удостоверенных акциями, и (или) об особенностях осуществления прав на акции, стороны которого обязуются осуществлять определенным образом эти права и (или) воздерживаться от осуществления этих прав.

В п. 3 ст. 8 Федерального закона «Об обществах с ограниченной ответственностью» от 8 февраля 1998 г. № 14-Ф3 (далее - Закон об ООО) установлено, что договор об осуществлении прав участников общества вправе заключить учредители (участники) общества.

Из анализа вышеприведенных норм можно сделать следующие выводы.

Во-первых, прямого указания на то, что только участники хозяйственных обществ могут быть стороной корпоративного договора, в законодательстве не содержится. В свою очередь, предпосылок для расширительного толкования категории «субъект корпоративного договора» тоже нет.

Во-вторых, для определения круга субъектов, имеющих право на заключение корпоративных соглашений, в ГК РФ, Законе об АО, Законе об ООО использованы разные подходы: в норме о корпоративном договоре содержится прямое указание на участников хозяйственного общества; в норме об акционерном соглашении - на лиц, имеющих права, удостоверенные акциями, и (или) права распоряжения ими; в норме о договоре об осуществлении прав участников общества с ограниченной ответственностью - на учредителей (участников) хозяйственного общества.

1 Гражданский кодекс Российской Федерации (часть первая) : федер. закон от 30 нояб. 1994 г. № 51Ф3 // Собрание законодательства РФ. 1994. № 32. Ст. 3301 . 
Содержание формулировок, используемых в ГК РФ и Законе об АО, можно считать тождественным, поскольку лица, имеющие права, удостоверенные акциями, и (или) права распоряжения ими, и есть участники хозяйственного общества (в данном случае акционеры). В связи с этим главный вопрос вызывает прямое указание в Законе об ООО на учредителей как участников корпоративного договора, которого нет ни в Законе об АО, ни в ГК РФ. Из системного толкования ст. $67^{2}$ ГК РФ, ст. $32^{1}$ Закона об АО, п. 3 ст. 8 Закона об ООО не представляется возможным однозначно ответить на вопросы о том, имеют ли право учредители акционерных обществ заключить корпоративный договор и насколько предоставление учредителям хозяйственного общества (как акционерного общества, так и общества с ограниченной ответственностью) права заключать корпоративный договор вообще соответствует действующему законодательству.

Думается, что предпосылок для ограничения прав учредителей акционерного общества на заключение корпоративного договора при одновременном предоставлении права заключить корпоративный договор учредителям общества с ограниченной ответственностью нет.

По нашему мнению, фрормулировку, используемую в п. 3 ст. 8 Закона об ООО, можно объяснить следующим. Принятие нормы о договоре об осуществлении прав участников общества с ограниченной ответственностью произошло одновременно с исключением из Закона об ООО норм об одном из учредительных документов общества с ограниченной ответственностью - учредительном договоре. Фактически договор об осуществлении прав участников общества с ограниченной ответственностью пришел на смену учредительному договору в обществах с ограниченной ответственностью. Между тем многие вопросы управления в обществе с ограниченной ответственностью регулировались именно этим документом. В связи с вышесказанным думается, что законодатель для определения круга субъектов договора об осуществлении прав участников общества с ограниченной ответственностью использовал тот же подход, что и при установлении правового регулирования учредительного договора, в связи с чем формулировка, используемая в п. 3 ст. 8 Закона об ООО, не несет в себе какой-то особый, двойной смысл.

Так или иначе непоследовательный в законодательстве подход к установлению круга участников корпоративных соглаше- ний привел к тому, что в науке сорормировалось два мнения по вопросу заключения корпоративных договоров учредителями хозяйственного общества: одно, основанное на буквальном толковании действующего законодательства, допускающее участие учредителей хозяйственного общества в заключении корпоративного договора, и другое, отрицающее такую возможность и аргументированное тем, что до момента создания хозяйственного общества его учредители не обладают корпоративными правами, по поводу осуществления которых они могли бы заключить корпоративный договор [1, с. 15 ; 8, с. 490]. По итогам решения этой проблемы К. О. Осипенко сделан вывод о том, что учредители хозяйственного общества могут заключить корпоративный договор в качестве сторон предварительного договора [9, с. 80].

Нужно согласиться с тем, что до создания хозяйственного общества его учредители не обладают корпоративными правами, а значит, не могут заключить корпоративный договор в том содержании, в котором он определен в ст. $67^{2}$ ГК РФ. Между тем заключение учредителями хозяйственного общества предварительного корпоративного договора, по нашему мнению, влечет излишние трудности. В связи с этим более целесообразным представляется прямо закрепить в нормах о корпоративных соглашениях положение о том, что договор, заключенный между учредителями хозяйственного общества, вступает в силу с момента учреждения хозяйственного общества, так же как это, например, установлено в семейном законодательстве для определения порядка вступления в силу брачного договора между лицами, желающими вступить в брак.

В качестве возможных участников корпоративного договора в науке часто называются будущие участники хозяйственного общества.

Следует отметить, что еще в законопроекте об акционерном соглашении ${ }^{2}$ было предусмотрено, что акционерное соглашение может быть заключено лицом, не являющимся акционером на дату заключения акционерного соглашения, в отношении акций, которые это лицо приобретет в будущем. Данная идея нашла поддержку и среди ученых, что подтверждается принятым 29 октября 2007 г. экспертным заключением Совета при Президенте Российской Федерации по кодификации и совершенствованию гражданского законодательства, в котором

\footnotetext{
${ }^{2}$ Вестник гражданского права. 2008. № 1. С. 128.
} 
указано, что «проект обоснованно исходит из того, что акционерное соглашение может заключаться как между акционерами, так и будущими (потенциальными) акционерами» ${ }^{3}$.

Ученые, поддерживающие идею заключения корпоративного договора будущими участниками хозяйственных обществ, исходят из того, что непреодолимых препятствий для заключения корпоративных соглашений указанными лицами нет [4, с. 10; 5, с. 107]. Напротив, отмечают они, заключение таких соглашений «позволит решить проблему осуществления прав акционера в период между заключением договора об отчуждении акций и переходом прав на них, когда между этими событиями существует значительный разрыв во времени» [10, с. 12].

Вместе с тем даже сторонники этой идеи ввиду отсутствия прямого указания в законе на возможность заключения корпоративного договора данными субъектами отмечают возможные риски признания таких соглашений недействительными. В этой связи в литературе было сделано предложение обеспечивать наличие возможности исполнения обязательства из корпоративного договора заключением предварительного или основного договора купли-продажи акций, доли в уставном капитале хозяйственного общества [4, с. 10]. Также в качестве еще одного варианта ученые предлагали заключать предварительный корпоративный договор [9, с. 90; 11, с. 69].

Специалисты в соере корпоративного права, возражающие против расширительного толкования понятия «субъект корпоративного договора», как правило, ссылаются на отсутствие у будущего участника хозяйственного общества при заключении договора прав на акции, долю в уставном капитале общества с ограниченной ответственностью, т. е. предмета договора [2, с. 70].

Следует отметить, что вопрос участия в качестве стороны корпоративного договора будущих участников хозяйственного общества особенно активно обсуждался до появления в ГК РФ нормы о корпоративном договоре. В настоящее время п. 9 ст. $67^{2}$ ГК РФ предусмотрено, что кредиторы общества и иные третьи лица могут заключить договор с участниками хозяйственного общества, по которому последние в целях обеспечения охраняемого законом интереса таких третьих лиц обязуются осуществлять свои корпоративные права определенным образом или воздерживаться (отказаться) от их осуществления. К этому договору соот-

${ }^{3}$ Вестник гражданского права. С. 152. ветственно применяются правила о корпоративном договоре.

Из системного толкования пп. 1 и 9 ст. $67^{2}$ ГК РФ следует, что корпоративный договор заключается между участниками хозяйственного общества, тогда как между участниками хозяйственного общества и третьими лицами заключается договор, к которому применяются правила о корпоративном договоре, т. е. договор, отличный по своей правовой природе от корпоративного договора. В этой связи третьи лица, имеющие охраняемый законом интерес (будущие участники хозяйственного общества, инвесторы, кредиторы, иные третьи лица), не могут быть стороной собственно корпоративного договора.

Однако вместе с тем нельзя не отметить, что интерес будущих участников корпоративного договора отличен от интереса, которым обладают иные третьи лица, поскольку презюмируется, что будущий участник, в отличие от них, впоследствии приобретет статус участника хозяйственного общества. Соответственно, следует согласиться с авторами, по мнению которых будущие участники хозяйственного общества могут заключить предварительный корпоративный договор [9, с. 90; 11, с. 69].

В качестве еще одного субъекта корпоративного договора в литературе называют номинального держателя ценных бумаг. Согласно п. 1 ст. $8^{3}$ Федерального закона «О рынке ценных бумаг» от 22 апреля 1996 г. № 39-Ф3 (далее - Закон о рынке ценных бумаг), номинальным держателем ценных бумаг является депозитарий, на лицевом счете (счете депо) которого учитываются права на ценные бумаги, принадлежащие иным лицам. Пунктом 4 ст. 83 Закона о рынке ценных бумаг предусмотрено, что номинальный держатель, учитывающий права на ценные бумаги лиц, осуществляющих права по ценным бумагам, вправе совершать действия, связанные с осуществлением этих прав, без доверенности в соответствии с полученными им указаниями (инструкциями) от таких лиц.

Таким образом, из приведенных выше законодательных формулировок следует вывод о том, что определять порядок осуществления корпоративных прав номинальный держатель не вправе, а потому не может быть наделен правом заключать корпоративный договор.

В качестве стороны корпоративного договора в литературе выделяют также доверительного управляющего. Частью 11 ст. 5 Закона о рынке ценных бумаг установлено, что управляющий по своему усмотрению осуществляет все права, закрепленные цен- 
ными бумагами, являющимися объектом доверительного управления, за исключением случаев, когда договором доверительного управления установлено ограничение на осуществление права голоса.

Ученые, которые рассматривают доверительного управляющего ценными бумагами в качестве стороны корпоративного договора, справедливо указывают на п. 2 ст. 1012 ГК РФ, согласно которому доверительный управляющий, осуществляя доверительное управление имуществом, вправе совершать в отношении этого имущества в соответствии с договором доверительного управления любые юридические и фактические действия в интересах выгодоприобретателя [7, с. 153]. С учетом того что период управления может быть достаточно длительным по времени, а в целях сохранения имущества доверительный управляющий должен управлять им как можно более эфффективно, ему для этого предоставляются практически все те же инструменты, что и собственнику имущества.

Указанное свидетельствует о том, что доверительный управляющий ценными бумагами имеет право заключать корпоративный договор, за исключением случая, когда соответствующие права управляющего ограничены договором с выгодоприобретателем.

Наконец, еще одним участником корпоративного договора в литературе называют хозяйственное общество, по поводу осуществления прав участия в котором заключается договор [6, с. 35; 12, с. 11].

По нашему мнению, хозяйственное общество не может быть субъектом корпоративного договора. Как справедливо отмечают ученые, несмотря на то что права на акции, долю в уставном капитале общества с ограниченной ответственностью могут переходить непосредственно к самому обществу, распоряжение ими сведено к минимуму [14, c. 77]. Вызывает также вопрос, какое лицо и в каком порядке будет выражать волю самого хозяйственного общества. Если это будут органы управления, то это может создать еще больше корпоративных конфликтов, в целях разрешения которых в большинстве случаев и заключается корпоративный договор. Также примечательно, что еще при обсуждении законопроекта об акционерном соглашении подобная возможность категорически отвергалась Советом при Президенте Российской Федерации по кодификации и совершенствованию гражданского законодательства.

Таким образом, анализ действующего законодательства и доктрины права позволяет сделать вывод о том, что абсолютное право на заключение корпоративного договора предоставлено только участникам хозяйственного общества. При этом при соблюдении определенных условий к субъектам, которые наделены правом заключить корпоративный договор, следует отнести учредителей хозяйственного общества, договор между которыми вступает в силу только с момента создания хозяйственного общества; будущих участников хозяйственного общества, заключивших предварительный корпоративный договор; доверительного управляющего ценными бумагами, за исключением случаев, когда его права на осуществление соответствующих полномочий ограничены договором доверительного управления.

\section{СПИСОК ИСПОЛЬЗОВАННОЙ ЛИТЕРАТУРЫ}

1. Ломакин Д. В. Договор об осуществлении прав участников хозяйственных обществ как новелла корпоративного законодательства / Д. В. Ломакин // Вестник Высшего Арбитражного Суда Российской Федерации. - 2009. - № 8. - С. 6-26.

2. Федоров С. И. Правовое регулирование корпоративных договоров и модернизация гражданского права России / С. И. Федоров / / Вестник гражданского права. - 2013. - № 1. - С. 52-96.

3. Шиткина И. С. Соглашения акционеров (договоры об осуществлении прав участников) как источник регламентации корпоративных отношений / И. С. Шиткина / / Хозяйство и право. — 2011. — № 2. - С. 35-46.

4. Кокорин А. С. Будущий акционер как сторона акционерного соглашения по российскому законодательству / А. С. Кокорин / / Безопасность бизнеса. - 2011. - № 2. - С. 9-11.

5. Рублев В. В. Понятие и правовая характеристика акционерного соглашения как гражданско-правового договора, регулируемого гражданским законодательством России / В. В. Рублев / / Современное право. 2010. - № 9. - С. 102-109.

6. КорневИ. Акционерное соглашение: заключение, содержание иисполнение / И. Корнев, В. Арутюнян // Корпоративный юрист. - 2010. - № 1. - С. 32-37.

7. Грибкова Т. В. Акционерные соглашения как средство правового регулирования корпоративных отношений : дис. .... канд. юрид. наук : 12.00.03 / Т. В. Грибкова. - М., 2011. - 238 с.

8. Афранасьева Е. Г. Корпоративное право : учеб. курс / Е. Г. Афанасьева, В. Ю. Бакшинскас, Е. П. Губин ; отв. ред. И. С. Шиткина. - М. : КноРус, 2011. - 1120 с.

9. Осипенко К. О. Договор об осуществлении прав участников хозяйственных обществ в российском и английском праве / К. О. Осипенко. - М. : Инфотропик Медиа, 2016. -173 с.

10. Плеханов В. К вопросу о соглашениях акционеров : интервью / В. Плеханов, М. Распутин, В. Кузнецов ; беседовали И. Балабуев, А. Каширин // ЭЖ-Юрист. - 2009. - № 44. - С. 12-13. 
11. Черленяк Р. Н. Договор об осуществлении прав участников ООО. Проблемы заключения и последствия нарушения / Р. Н. Черленяк / / Арбитражная практика. - 2012. — № 9. - С. 66-70.

12. Бородкин В. Г. Гражданско-правовое регулирование корпоративного договора : автореф. дис. .... канд. юрид. наук : 12.00 .03 / В. Г. Бородкин. - М., 2015. - 31 с.

13. Долинская В. В. Изменения в акционерном законодательстве / В. В. Долинская // Законы России: опыт, анализ, практика. - 2006. - № 11. - С. 72-80.

\section{REFERENCES}

1. Lomakin D. V. An Agreement of the Enforcement of the Rights of Participants of Business Entities as a Novel of the Corporate Legislation. Vestnik Vysshego Arbitrazhnogo suda RF = Herald of the Supreme Arbitrazh Court of Russia, 2009, no. 8, pp. 6-26. (In Russian).

2. Fedorov S. I. Legal Regulation of Corporate Agreements and Reforms of Civil Law in Russia. Vestnik grazhdanskogo prava = Civil Law Review, 2013, no. 1, pp. 52-96. (In Russian).

3. Shitkina I. S. Shareholder Agreements (Agreements on the Exercise of Participants' Rights) as a Source of Regulation of Corporate Relations. Khozyaistvo i pravo = Economy and Law, 2011, no. 2, pp. 35-46. (In Russian).

4. Kokorin A. S. Future Shareholder as a Party a Shareholder Agreement under the Russian Law. Bezopasnost' biznesa = Business Security, 2011, no. 2, pp. 9-11. (In Russian).

5. Rublev V. V. Concept and the legal description of the shareholders agreement as a civil-legal contract regulated by the civil legislation of the Russia. Sovremennoe pravo = Modern law, 2010, no. 9, pp. 102-109. (In Russian).

6. Kornev I., Arutyunyan V. Shareholder Agreement: Conclusion, Content and Execution. Korporativnyi yurist = Corporate Lawyer, 2010, no. 1, pp. 32-37. (In Russian).

7. Gribkova T. V. Aktsionernye soglasheniya kak sredstvo pravovogo regulirovaniya korporativnykh otnoshenii. Kand. Diss. [Corporate Agreements as a Means of Legal Regulation of Corporate Relations. Cand. Diss.]. Moscow, 2011. $238 \mathrm{p}$.

8. Afanas'eva E. G., Bakshinskas V. Yu., Gubin E. P.; Shitkina I. S. (ed.). Korporativnoe pravo [Corporate Law]. Moscow, KnoRus Publ., 2011. 1120 p.

9. Osipenko K. O. Dogovor ob osushchestvlenii prav uchastnikov khozyaistvennykh obshchestv $v$ rossiiskom $i$ angliiskom prave [An Agreement of the Exercise of Rights of Participants of Business Entities in the Russian and English Law]. Moscow, Infotropik Media Publ., 2016. 173 p.

10. Plekhanov V., Rasputin M., Kuznetsov V.; Balabuev I., Kashirin A. (eds). On the Issue of Agreements of Shareholders. EJ-Jurist, 2009, no. 44, pp. 12-13. (In Russian).

11. Cherlenyak R. N. Agreement on the Exercise of Rights of an LLC. The Issues of Conclusion and the Consequences of the Breach. Arbitrazhnaya praktika = Arbitrage Practice, 2012, no. 9, pp. 66-70. (In Russian).

12. Borodkin V. G. Grazhdansko-pravovoe regulirovanie korporativnogo dogovora. Avtoref. Kand. Diss. [Civil Law Regulation of Corporate Agreement. Cand. Diss. Thesis]. Moscow, 2015. 31 p.

13. Dolinskaya V. V. Changes in the Corporate Legislation. Zakony Rossii: opyt, analiz, praktika = Law of Russia: Experience, Analysis, Practice, 2006, no. 11, pp. 72-80. (In Russian).

\section{Информация об авторе}

Гребенюк Мария Андреевна - аспирант, кафедра предпринимательского и финансового права, Байкальский государственный университет, 664003, г. Иркутск, ул. Ленина, 11, e-mail: magni+333@list.ru.

\section{Для цитирования}

Гребенюк М. А. К вопросу о субъектном составе корпоративного договора / М. А. Гребенюк // Известия Байкальского государственного университета. - 2017. - T. 27, № 4. - C. 562-567. - DOI: $10.17150 / 2500-2759.2017 .27(4) .562-567$.

\section{Author}

Maria A. Grebenyuk - PhD Student, Department of Business and Financial Law, Baikal State University, 11 Lenin St., 664003, Irkutsk, Russian Federation, e-mail: magnit333@list.ru.

\section{For citation}

Grebenyuk M. A. About the Problem of Parties to the Corporate Agreement. Izvestiya Baykal'skogo gosudarstvennogo universiteta $=$ Bulletin of Baikal State University, 2017, vol. 27, no. 4, pp. 562-567. DOI: 10.17150/2500-2759.2017.27(4).562-567. (In Russian). 